\title{
Rapidly fatal pulmonary fibrosis: the accelerated variant of interstitial pneumonitis
}

\author{
DAVID S PRATT, ${ }^{1}$ MARVIN I SCHWARTZ, JOHN J MAY, AND ROBERT B DREISIN \\ From the Division of Pulmonary Sciences, University of Colorado Medical Centre, \\ and Veterans Administration Hospital, Denver, Colorado, USA
}

ABSTRACT We sought to explore immunological factors in patients who died with rapidly fatal fibrosing lung diseases (Hamman-Rich syndrome). A retrospective review of cases of interstitial lung disease showed 12 recent deaths from Hamman-Rich syndrome.

The mean age was 62 , men outnumbering women $3: 1$. Five patients had proved collagen vascular disease (rheumatoid arthritis three, lupus two). Four others had a history of allergic disorders, syphilis, chronic eosinophilia, or hypersensitivity reactions.

One patient showed disappearance of immunofluorescence as fibrosis advanced, which has not previously been reported. The study suggests a possible aetiological link between disorders of immunity and Hamman-Rich syndrome. The evidence also supports the notion that Hamman-Rich syndrome is an accelerated variant of the more indolent interstitial pneumonias.

Hamman and Rich $(1933,1944)$ reported cases of fulminant pulmonary fibrosis leading to death within six months. Following these reports, the medical literature grew (Eder et al, 1945; Potter and Gerber, 1948; Beams and Harmos, 1949; Golden and Tullis, 1949; Katz and Auerbach, 1951) and it became apparent that the rapid downhill course was the exception rather than the rule (Rubin and Lubliner, 1957). Interstitial pneumonitis leading to fibrosis is recognised after various injuries to the lung, including the collagen vascular diseases (Crystal et al, 1976). Many patients, however, have no discernible aetiology for their illness (Crystal et al, 1976). The clinical course of idiopathic interstitial pneumonitis (IIP) may evolve in several different ways. A progressive interstitial inflammation resulting in fibrosis with a slow decline is the most common (Rubin and Lubliner, 1957; Stack et al, 1972; Crystal et al, 1976) but cases have been reported showing resolution of the disease with or without treatment (Livingstone et al, 1964), while a third group follows the fulminant course described by Hamman and Rich.

\footnotetext{
'Present address: Mary Imogene Bassett Hospital, Cooperstown, New York 13326.

This work was supported in part by NIH Grant Number 5 RO1 HL 19018-02.
}

Recent work from our laboratory has suggested an immunological aetiology for IIP. Dreisin et al (1978) showed that patients with IIP have circulating immune complexes. Schwarz et al (1978) showed the presence of tissue immune complexes within alveolar walls of these patients. Other authors have shown the presence of immune complexes in interstitial pneumonitis associated with various collagen vascular diseases (DeHoratius et al, 1972; Pertschuk et al, 1977). These studies suggest that the mechanism for IIP may be inmmunologically mediated by immune complexes. Both Dreisin and Schwarz pointed out less apparent immunological activity in patients with densely fibrotic lungs. They found that the more pronounced the cellularity, the more likely the patient was to have circulating immune complexes as well as alveolar wall IgG and complement deposition. In patients with predominant fibrosis immune complexes were absent from the lungs and serum (Dreisin et al, 1978; Schwarz et al, 1978).

The fulminant form of interstitial pneumonitis shows scant cellularity and striking fibrosis at necropsy. Preliminary data from previously published studies have suggested absent immune complex markers (Dreisin et al, 1978; Schwarz et al, 1978), raising the question as to whether HammanRich syndrome bears any aetiological similarity to IIP. We thought that although they might be 
similar, once the acute inflammatory elements were replaced by fibroblastic proliferation the immunological markers might well be gone. The fibrosis probably signalled the end of the lung's ability to react to immune mediated injuries. To determine the immunological background of the rapidly progressive form of this disease, we studied 12 cases of fulminating interstitial pneumonitis (Hamman-Rich syndrome).

\section{Methods}

We reviewed the records from six major Denver hospitals and the experiences of 20 pulmonary physicians in the greater Denver area. Once cases were found, they were further screened to include only those with historical, radiographic, and histological proof of interstitial lung disease. The course had to be rapid, and death result from the disease or a direct complication thereof. From well over 175 cases of IIP known to us, only 12 met these criteria. In addition to routine laboratory evaluation, all patients had rheumatoid or antinuclear factors, or both, measured. Six subjects had direct immunofluorescence of biopsied lung tissue performed by previously described methods (Schwarz et al, 1978). Five patients had circulating immune complexes measured by the $\mathrm{Raji}$ cell radioimmunoassay (Dreisin et al, 1978). Patient 11 had lung biopsy and was studied six months before death and again after death.

\section{Results}

Table 1 shows the age, race, sex, serological data, and survival from the first visit to the doctor for pulmonary complaints. The mean age was 62 years (range 27 to 82). Men outnumbered women $3: 1$. The racial distribution favoured Spanish surnamed individuals, largely reflecting Colorado's population. Six of 11 patients studied had a rheumatoid factor titre of $1: 40$ or greater $(54 \%)$, and three had an antinuclear antibody titre of $1: 40$ or more $(27 \%)$. Clinically apparent arthritis was noted in five patients, and four of those had raised titres of rheumatoid factor. Cases 10 and $\delta$ 11 met all major criteria for systemic lupus erythe- $\vec{\circ}$ matosus (Cohen et al, 1971). Three patients (cases 1,2 , and 12) with positive rheumatoid factor and arthritis met criteria for rheumatoid arthritis (Williams, 1974). The other two patients (4 and 8) had arthritis and a positive rheumatoid factor but $\omega$ did not fit a specific diagnosis entity. All cases or studied had raised sedimentation rates and a slight leukocytosis.

The mean survival after lung biopsy was 12 윽 weeks. The average survival from onset of symptoms was 4.7 months. Eight patients survived $\bigcirc$ from one to three months and the other four lived $\overrightarrow{0}$ up to 18 months. In reviewing the radiographs of $\mathbb{\Phi}$ our patients we found that two (1 and 11) had $\vec{\oplus}$ interstitial infiltrates five and 11 years before onset of symptoms. Patient 1 was a coal miner with rheumatoid arthritis and patient 11 had systemic lupus erythematosus. Before this study their lung disease was thought to be newly diagnosed. These two patients appear to have had asymptomatic, longstanding interstitial lung disease terminating in a fulminant course. Patients $1,2,4,5,9$, and $11 \overrightarrow{\bar{\sigma}}$ had direct immunofluorescence performed, patients 1 and 11 being positive. Patient 1 had IgG and IgM within alveolar walls; patient 11 was positive for IgG and IgA. Five patients $(2,3,7,9$, and 11) had circulating immune complex assays performed; only patient 11 was positive.

The cause of death in patients with accelerated pulmonary fibrosis were ventilatory failure (4), pneumonia (3), pneumothorax (2), extubation with emergency tracheostomy (1), ethrane toxicity, haemorrhage (1), and pulmonary emboli (1).

Table 1 Characteristics of patients studied

\begin{tabular}{|c|c|c|c|c|c|c|c|}
\hline Case No & Diagnosis & Age & $\operatorname{Sex}$ & Ethnic/race & $\begin{array}{l}\text { Rheumatoid } \\
\text { factor titre }\end{array}$ & $\begin{array}{l}\text { Antinuclear } \\
\text { factor titre }\end{array}$ & $\begin{array}{l}\text { Survival from onset } \\
\text { of symptoms (months) }\end{array}$ \\
\hline $\begin{array}{r}1 \\
2 \\
3 \\
4 \\
5 \\
6 \\
7 \\
8 \\
9 \\
10 \\
11 \\
12\end{array}$ & $\begin{array}{l}\text { Rheumatoid arthritis } \\
\text { Rheumatoid arthritis } \\
\text { Hay fever } \\
\text { Diffuse arthralgia } \\
\text { Hypersensitivity to birds } \\
\text { None } \\
\text { Chronic eosinophilia } \\
\text { Penicillin allergy } \\
\text { Syphilis } \\
\text { Lupus erythematosis } \\
\text { Lupus erythematosis } \\
\text { Rheumatoid arthritis }\end{array}$ & $\begin{array}{c}73 \\
69 \\
27 \\
61 \\
53 \\
77 \\
82 \\
64 \\
36 \\
75 \\
68 \\
62 \\
\text { Mean age-62 years }\end{array}$ & $\begin{array}{l}\mathbf{M} \\
\mathbf{M} \\
\mathbf{M} \\
\mathbf{M} \\
\mathbf{M} \\
\mathbf{M} \\
\mathbf{M} \\
\mathbf{M} \\
\mathbf{F} \\
\mathbf{F} \\
\mathbf{F} \\
\mathbf{M}\end{array}$ & $\begin{array}{l}\text { Spanish } \\
\text { White } \\
\text { Spanish } \\
\text { White } \\
\text { White } \\
\text { Spanish } \\
\text { Spanish } \\
\text { American Indian } \\
\text { Black } \\
\text { White } \\
\text { White } \\
\text { White }\end{array}$ & 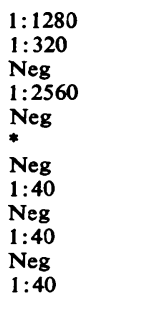 & $\begin{array}{l}1: 40 \\
\text { Neg } \\
\text { Neg } \\
\text { Neg } \\
\text { Neg } \\
\text { Neg } \\
\text { Neg } \\
\text { Neg } \\
\text { Neg } \\
1: 160 \\
1: 512 \\
*\end{array}$ & $\begin{array}{l}6 \cdot 5 \\
0 \cdot 6 \\
11 \\
1 \\
3 \cdot 0 \\
0 \cdot 3 \\
2 \\
1 \\
18 \\
1 \\
11 \\
1 \\
\text { Mean-4.70 }\end{array}$ \\
\hline
\end{tabular}

*Test not performed. 
Assisted ventilation was carried out in eight of 12 patients. Mean patient survival after ventilatory support was 10.3 days. Pneumothorax occurred at some time during the illness in half of our group. One patient (9) was put on extracorporeal membrane oxygenation. She died of ethrane toxicity and haemorrhage. Four patients were diabetic. The prevalence of this feature is considerably higher than in the age, sex, and racially matched cohort from the general population (Wilkerson and Krall, 1947).

In five subjects $(3,5,6,7$, and 9$)$ there were no obvious immunological markers; however, a review of their past medical histories disclosed suggestive data (table 2)-patient 6 is the only case in which immune-related disease was totally absent.

Patient 11 provided us with a unique opportunity to follow the course of interstitial pneu-

Table 2 Immunological histories of patients with negative serology

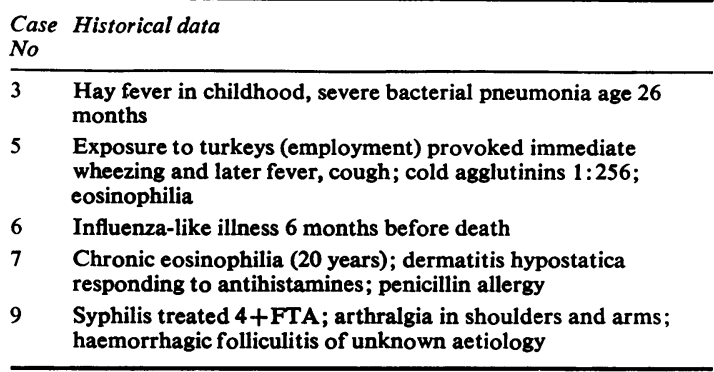

monia. She met the American Rheumatologic Association criteria for systemic lupus erythematosus, and first presented with pleuritis 11 months before death. Pronounced interstitial infiltrates developed shortly after her pleuritis. She became dyspnoeic and hypoxaemic. An open lung biopsy (fig 1) showed a cellular interstitial pneumonitis with minimal fibrosis. Lung immunofluorescence disclosed positive staining for IgG and $\operatorname{IgA}$ in alveolar walls (fig 2). The patient had progressive dyspnoea and fatigue despite high dose corticosteroids and cyclophosphamide treatment. Her declining $\mathrm{PaO}_{2}$ and dyspnoea were complicated by well-documented pulmonary emboli. Mechanical ventilation was begun and death ensued in ten days. Radiographs showed increasing interstitial infiltrates until her death (figs 3 and 4). Postmortem lung histology showed dense fibrosis, scant cellular elements, and hyaline membranes (fig 5). Post-mortem immunofluorescence was negative (fig 6). This case progressed from an active cellular histopathology with positive immunofluorescence to a fibrotic non-fluorescent end-stage lung within six months.

\section{Discussion}

Interstitial pneumonitis occurring in association with rheumatoid arthritis, systemic lupus erythematosus, polymyositis/dermatomyositis, and scleroderma is well-known (Tomasi et al, 1962; Petty and Wilkins, 1966; Weaver et al, 1968; Eisenberg

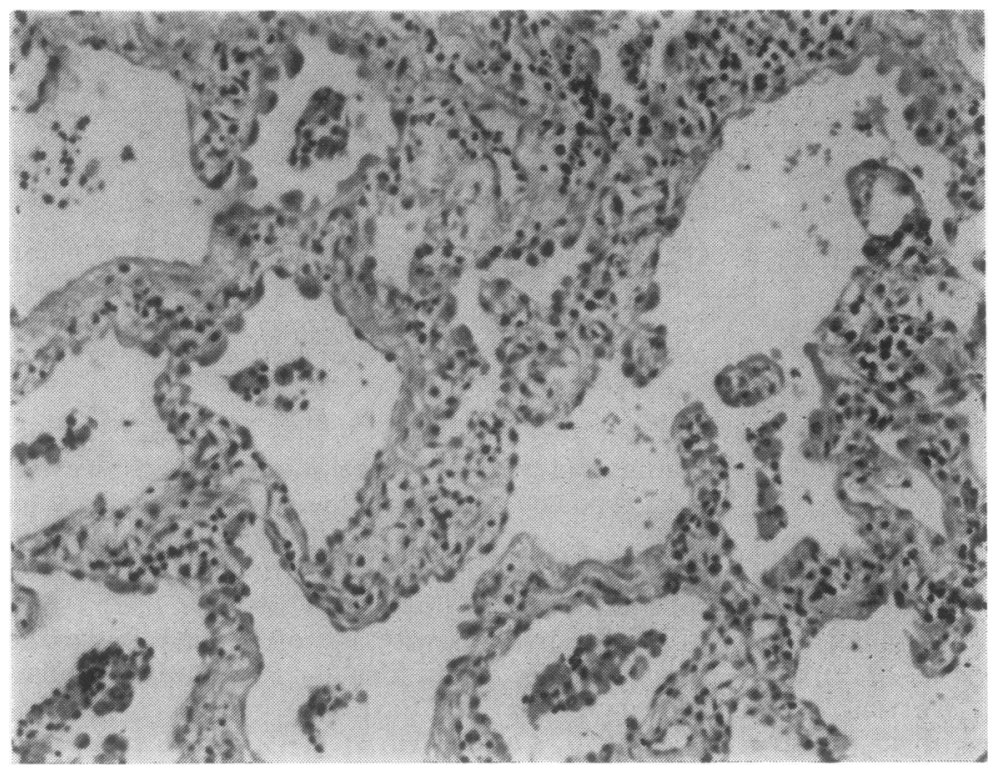

Fig 1 Patient 11. Open lung biopsy. Note widened alveolar septa and intra-alveolar macrophages. Fibrosis is absent. (Haematoxalin and eosin $\times 250$ ). 


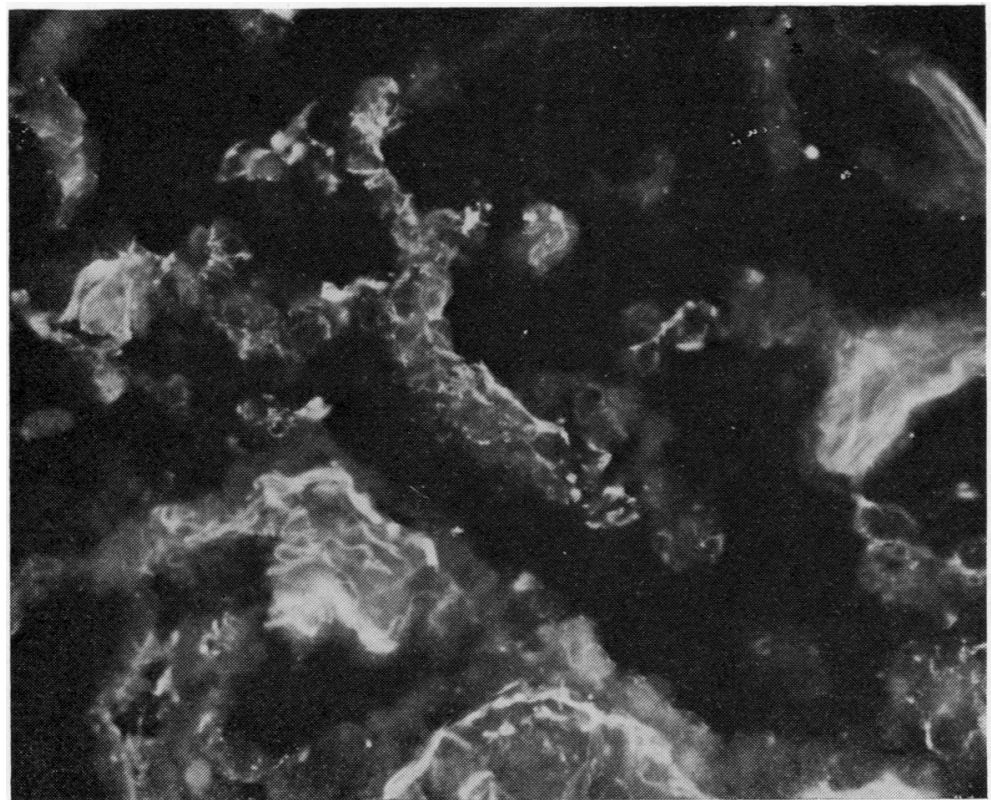

Fig 2 Patient 11.

Immunofluorescent preparation of anti-IgG stain of open lung biopsy. Note fine lace-like areas in upper middle field characteristic of alveolar capillary deposition of globulin. (Fluorescent microscopy $\times 450$ ).

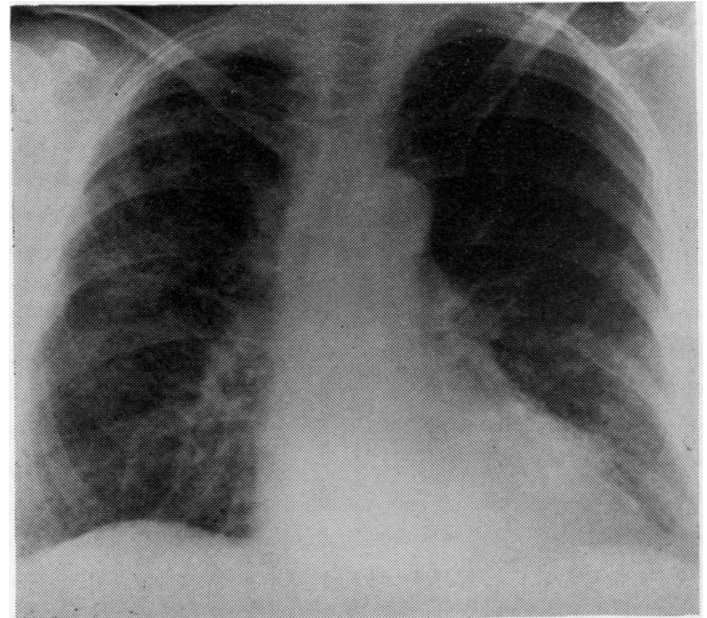

Fig 3 Patient11. Posteroanterior radiograph taken at onset of her symptoms. Note increased interstitial marking in right and left lungs (lower zones).

et al, 1973; Matthay et al, 1975; Schwarz et al, 1976). Interstitial pneumonitis may coexist with other autoimmune diseases, such as chronic active hepatitis (Turner-Warwick, 1968), Sjögrens syndrome (Turner-Warwick, 1974), autoimmune haemolytic anaemia (Scadding, 1977), idiopathic thrombocytopenic purpura (May et al, 1979), and Hashimoto's thyroiditis (Turner-Warwick and Doniach, 1965). The prevalence of a positive

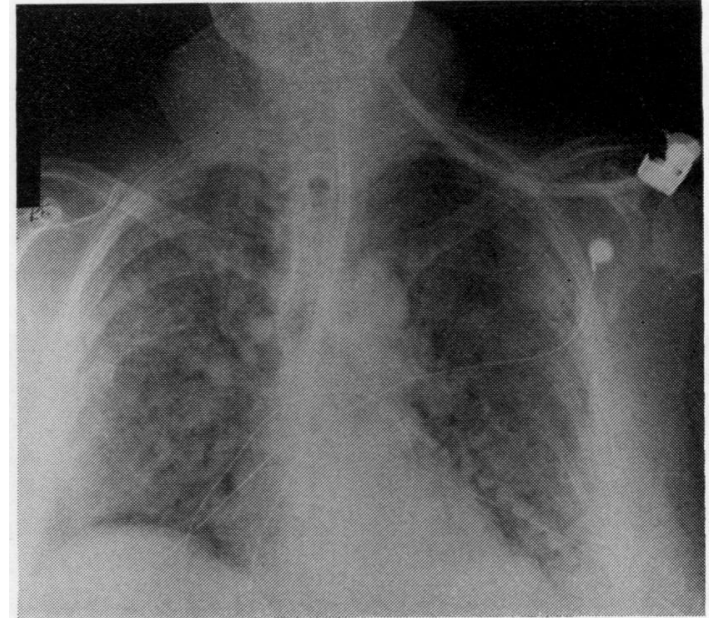

Fig 4 Patient 11. Anteroposterior radiograph near time of death. Diffuse fibrosis, infiltrates, and effusion at left are apparent.

rheumatoid factor in the idiopathic variety has been reported to be as high as $60 \%$ (Tomasi et al, $\mathbb{D}$ 1962). Nagaya studied a series of 20 patients with serological abnormalities and IIP without definable collagen vascular disorders (Nagaya et al, 1969). Clinically, patients with IIP often have low-grade fever, arthralgia, and myalgia. Raynaud's phenomenon and vasculitis have also been seen (Crystal et al, 1976; Turner-Warwick, 1977; Schwarz et al, 


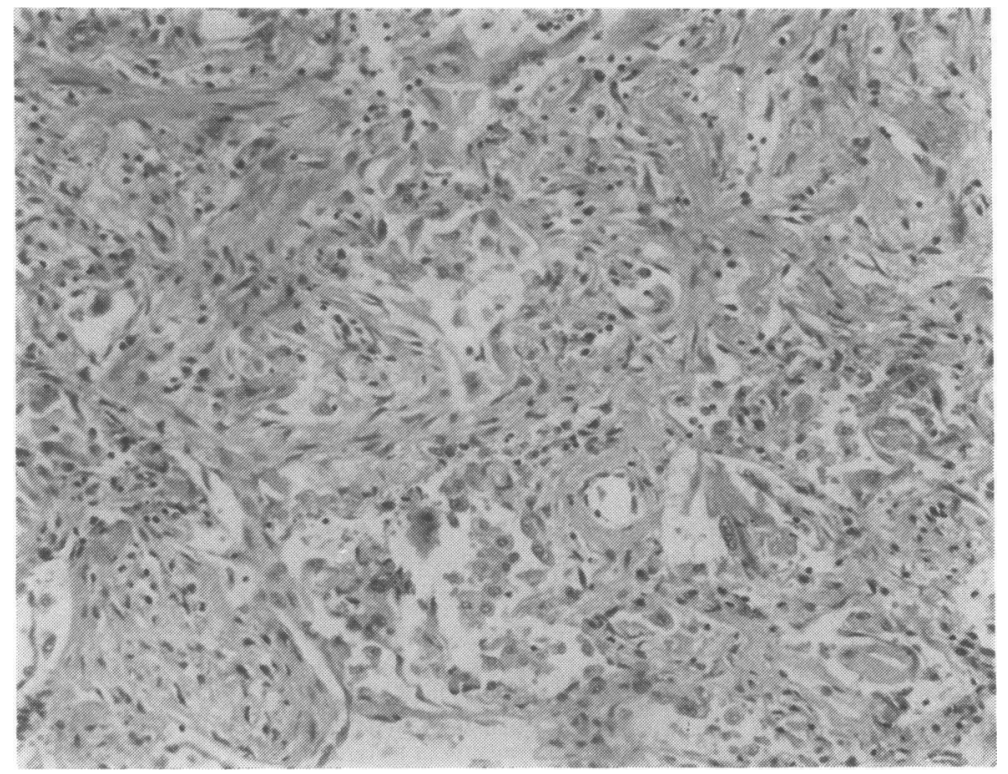

Fig 5 Patient 11. Necropsy specimen showing dense lung fibrosis and total effacement of normal architecture. ( $H$ and $E$ $\times 250)$.

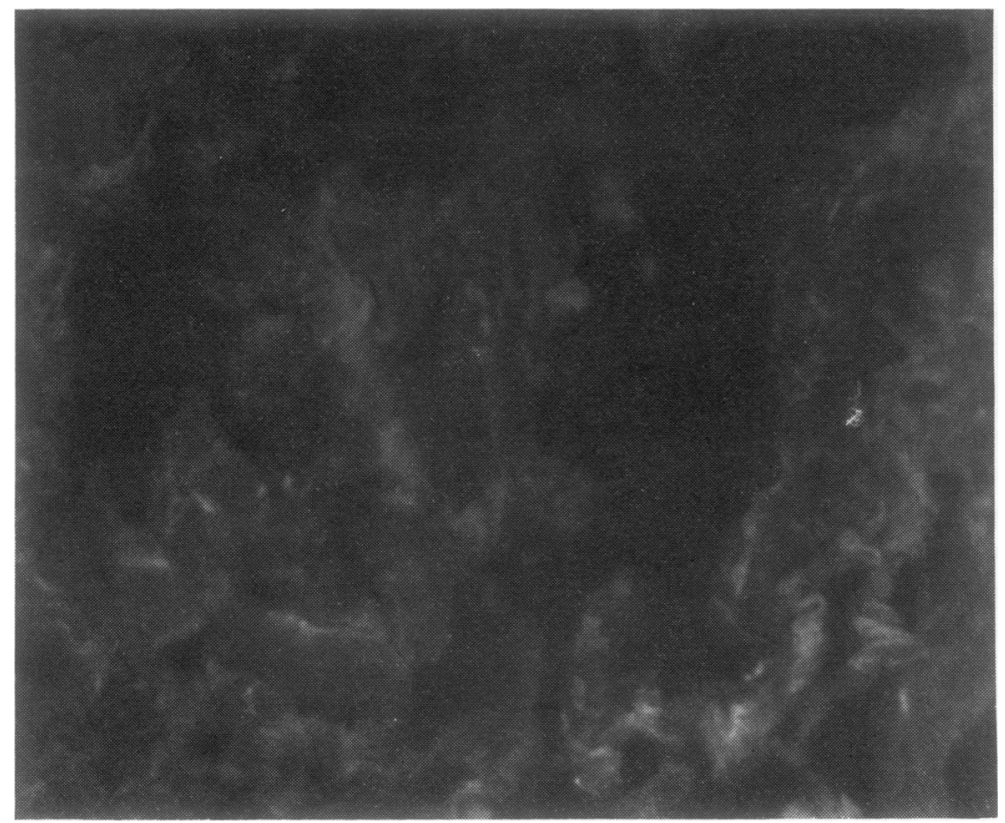

Fig 6 Patient 11. Post-mortem immunofluorescent microscopic photograph. Anti-IgG here is negative; only non-specific fluorescence shows. (Anti-IgG fluorescent microscopy $\times 450)$.

1978). The occurrence of similar findings in welldefined immune complex disease raises the possibility of a similar mechanism in IIP.

In the Hamman-Rich syndrome, immunological events have received less attention because of its low frequency and rapid course. Our series of 12 patients presented us with a unique opportunity to study this disease. The high prevalence of a well- defined collagen vascular disease was quite unexpected. In this group five subjects had a collagen vascular disease, and two other patients had positive rheumatoid factors but lacked the symptom complex of clinical rheumatoid disease. In addition, four subjects had previous or current illnesses that are associated with chronic antigen presentation and antibody stimulation. These in- 
clude asthma, chronic eosinophilia with dermatitis, syphilis, and bird-associated hypersensitivity.

In reviewing reports on Hamman-Rich syndrome we found several cases associated with diseases capable of chronic antibody stimulation (Hamman and Rich, 1933, 1944; Eder et al, 1945; Rubin and Lubliner, 1957; Callahan et al, 1952). These range from syphilis in Hamman and Rich's original reports to brucellosis in Callahan's (1952) work. The association of rheumatoid arthritis and Hamman-Rich syndrome has been reported by others (Rubin and Lubliner, 1957; Stack and Grant, 1965). The cases from our series and those cited above suggest that the aetiology of HammanRich syndrome, like IIP, is immunological. Interestingly, not all the diseases associated with a Hamman-Rich course are autoimmune. "Innocent bystander" injury of chronic immune complex deposition can be evoked in syphilis, brucellosis, trichinosis, and, possibly, bird-associated reactions. Lung damage may occur via a type III mechanism in all the examples thus far described. Work in our laboratory has shown that preformed immune complexes injected into rabbits' airways are taken up by macrophages (Pratt et al, 1979). The presence of the immune complexes also causes macrophages to release chemotactic factor (Roos et al, 1977). The polymorphonuclear response to chemotactic factor results in inflammation and oedema. The macrophage mediated inflammatory response may also trigger fibroblast proliferation and deposition of collagen (Brain et al, 1978). Patients with Hamman-Rich disease have a fulminant unchecked fibrosing process. It is possible to reason from our evidence that immune complexes are stimulating macrophages and causing inflammation leading to the fibrosis we see. Chronic immune complex deposition alone cannot explain this disease since many patients with rheumatoid arthritis, lupus erythematosus, and post-streptococcal glomerulonephritis are spared obvious lung involvement. Therefore, we postulate a host-specific response in our patients. They seem to lack the ability to check the relentless cycle of inflammation and fibrosis.

Patient 11 originally had a cellular interstitial pneumonia with positive immunofluorescence; four months later her lung was fibrotic and immunofluorescence was negative. This exemplified something we had suspected; that cellular disease represents the active immunological process, and when fibrosis occurs, the initiating process is complete and the immunological markers disappear. Nagaya et al (1969) had suggested this occurrence, but this is the first patient to have shown disap- pearance of immunofluorescence with increasing fibrosis.

The aetiology of Hamman-Rich syndrome is far from clear, although several cases are associated with a well-defined collagen vascular disease. Recent work by several authors has lent strength to a possible immunological aetiology in idiopathic interstitial pneumonia (Turner-Warwick, 1974; Dreisin et al, 1978; Schwarz et al, 1978; May et al, 1979). This study and our review of the other reported cases convinces us that Hamman-Rich syndrome is an accelerated variant of interstitial pneumonitis, and probably has an immunological basis similar to the more indolent forms. Finally, this study shows that cellular, immunofluorescent positive tissue can progress to fibrosis with the disappearance of immunofluorescence.

\section{References}

Beams, A J, and Harmos, O (1949). Diffuse progressive interstitial fibrosis of the lungs. American Journal of Medicine, 7, 425-430.

Brain, J B, Golde, D W, Green, G M, Massaro, D J, Valberg, P A, Ward, P A, and Werb, Z (1978). Biological potential of pulmonary macrophages. American Review of Respiratory Disease, 118, 435445.

Callahan, W P, sen, Sutherland, S G, Fulton, J K, and Kline, J R (1952). Acute diffuse interstitial fibrosis of the lungs (AMA). Archives of Internal Medicine, 90, 468-482.

Cohen, A S, Reynolds, W E, Franklin, E C, Kulka, J P, Ropes, M W, Shulman, L E, and Wallace, S C (1971). Preliminary criteria for the classification of systemic lupus erythematosis. Bulletin on the Rheumatic Diseases, 21, 643-648.

Crystal, R G, Fulmer, J K, Roberts, W C, Moss, M L, and Line, B R (1976). Idiopathic pulmonary fibrosis. Clinical histologic, radiographic, physiologic, scintigraphic, cytologic and biochemical aspects. Annals of Internal Medicine, 85, 769-788.

DeHoratius, R J, Abruzzo, J L, and Williams, R C (1972). Immunofluorescent and immunologic studies of rheumatoid lung. Archives of Internal Medicine, 129, 441-446.

Dreisin, R B, Schwarz, M I, Theophilopoulos, A N, and Stanford, R E (1978). Circulating immune complexes in the idiopathic interstitial pneumonias. New England Journal of Medicine, 298, 353-357.

Eder, H, Hawn, C V, and Thorn, G (1945). Report of a case of acute interstitial fibrosis of the lungs. Bulletin Johns Hopkins Hospital, 76, 163-171.

Eisenberg, H, Dubois, E L, Sherwin, R P, and Balchum, O J (1973). Diffuse interstitial lung disease in systemic lupus erythematosus. Annals of Internal Medicine, 79, 37-45.

Golden, A, and Tullis, I F, jun (1949). Diffuse interstitial fibrosis of the lungs. Military Surgeon, 105, 130-137. 
Hamman, L, and Rich, A R (1933). Clinical pathologic conference. International Clinics Forty-third Series I, 196.

Hamman, L, and Rich, A R (1944). Acute diffuse interstitial fibrosis of the lungs. Bulletin Johns Hopkins Hospital, 74, 177-212.

Katz, H L, and Auerbach, G (1951). Diffuse interstitial fibrosis of the lungs: report of a case with unusual features. Diseases of the Chest, 20, 366-377.

Livingstone, J L, Lewis, J G, Reid, L, and Jefferson, K E (1964). Diffuse interstitial pulmonary fibrosis. Quarterly Journal of Medicine, 33, 71-103.

Matthay, R A, Schwarz, M I, Petty, T L, Standford, R E, Gupta, R C, Sahn, S A, and Steigerwold, J C (1975). Pulmonary manifestations of systemic lupus erythematosus: a review of 12 cases of acute lupus pneumonitis. Medicine, 54, 397-409.

May, J J, Schwarz, M I, and Dreisin, R B (1979). The occurrence of idiopathic thrombocytopenic purpura in interstitial pneumonia. Annals of Internal Medicine, 90, 199-200.

Nagaya, H, Buckley, C E, and Sieker, H O (1969). Positive antinuclear factor in patients with unexplained pulmonary fibrosis. Annals of Internal Medicine, 70, 1135-1145.

Pertschuk, L P, Moccia, L F, Rosen, Y, Lyons, H, Marino, C M, Rashford, A A, and Wollschlager, C M (1977). Acute pulmonary complications in systemic lupus erythematosus. American Journal of Clinical Pathology, 68, 553-557.

Petty, T L, and Wilkins, M (1966). The five manifestations of rheumatoid lung. Diseases of the Chest, 49, 75-82.

Potter, B P, and Gerber, I E (1948). Acute diffuse interstitial fibrosis of the lungs. Archives of Internal Medicine, 82, 113-124.

Pratt, D S, Katilus, J, Dreisin, R B, Robinson, H M, and Schwarz, M I (1979). The use of fluorescent labelling to follow the fate of exogenously induced antigen in situ. Journal of Immunological Methods. In press.

Roos, H A, Keller, M W, Hess, H, and Coltier, H (1977). Alveolar macrophages: phagocytosis induced release of neutrophil chemotactic activity. In 16th Hanford Biology Symposium, edited by C L Sanders, p78. Technical Information Center, Energy Research \& Development Administration, Oakridge, Tennessee.

Rubin, E H, and Lubliner, R (1957). The HammanRich syndrome: review of the literature and analysis of 15 cases. Medicine, 36, 397-463.
Scadding, J G (1977). Fibrosing alveolitis with autoimmune haemolytic anaemia: two case reports. Thorax, 23, 134-139.

Schwartz, M I, Dreisin, R B, Pratt, D S, and Stanford, $R$ E (1978). Immunofluorescent patterns in the idiopathic interstitial pneumonias. Journal of Laboratory and Clinical Medicine, 91, 929-938.

Schwartz, M I, Matthay, R A, Sahn, S A, Stanford, R E, Marmorstein, B L, and Scheinhorn, D J (1976). Interstitial lung disease in polymyositis and dermatomyositis: an analysis of six cases and a review of the literature. Medicine, 55, 89-104.

Stack, B H R, Choo-Kang, Y F S, and Heard, B E (1972). The prognosis of cryptogenic fibrosing alveolitis. Thorax, 27, 535-542.

Stack, B H R, and Grant, I W B (1965). Rheumatoid interstitial lung disease. British Journal of Diseases of the Chest, 59, 202-211.

Tomasi, T B, jun, Fudenberg, H H, and Finby, N (1962). Possible relationship of rheumatoid factors and pulmonary disease. American Journal of Medicine, 33, 243-248.

Turner-Warwick, M (1968). Fibrosing alveolitis and chronic liver disease. Quarterly Journal of Medicine, 37, 133-149.

Turner-Warwick, M (1977). Interstitial lung disease and digital vasculitis. American Review of Respiratory Disease, 115 (abstract), 173.

Turner-Warwick, M (1974). Immunological aspects of systemic diseases of the lungs. Proceedings of the Royal Society of Medicine, 67, 541-547.

Turner-Warwick, M, and Doniach, D (1965). Autoantibody studies in interstitial pulmonary fibrosis. British Medical Journal, 1, 886-891.

Weaver, A L, Divertie, M B, and Titus, J L (1968). Pulmonary scleroderma. Diseases of the Chest, 54, $490-498$.

Wilkerson, H L C, and Krall, L P (1947). Diabetes in a New England town: a study of 3516 persons in Oxford, Mass. Journal of the American Medical Association, 135, 209-216.

Williams, R C (1974). Rheumatoid arthritis as a systemic disease. In Major Problems in Internal Medicine, vol 4. Saunders, Philadelphia.

Requests for reprints to: Marvin I Schwartz, MD, Veterans Administration Hospital, 1055 Clermont Street, Denver, Colorado 80220. 